\title{
Religiotainment: Tinjauan Semiotika dan Literasi Media Terhadap Animasi Nussa
}

\author{
Anwar Kurniawan \\ Universitas Gajah Mada \\ Alamat: Kaliurang St No.Km. 14.5, Krawitan, Ngemplak, Sleman, Yogyakarta (55584), Indonesia \\ E-mail: anwarkur20@mail.ugm.ac.id
}

\section{Religiotainment: A Media Literacy and Semiotics of Nussa Animation}

\begin{abstract}
This article discusses the religiotainment in Indonesia by the animation 'Nussa' which firmly adopts Islamic values and symbols in the midst of secular cartoons domination. Using new media platforms such as Youtube and TV, Nussa is here to accommodate the urban middle-class Muslim market. Two questions posed in this article are: how do new media create the possibility of representation of Islam? The author finds that the democratization of the media has encouraged people to voice out what was previously suppressed and even repressed under the Suharto's militaristic power, including the voices of Islam. On the other hand, the diversity of Islam itself causes the process of Islamization more dynamic. Nussa is one of many agents that enliven the contestation since the process of Islamization in Indonesia is in fact not controlled by any party. As a consequence, Nussa is not only received rave reviews from some Muslims, but also received unwelcome accusations from other Muslims at the same time.
\end{abstract}

Keywords: religiotainment; Nussa; semiotics

\section{ABSTRAK}

Artikel ini mendiskusikan tentang fenomena religiotainment di Indonesia lewat animasi Nussa yang secara tegas mengadopsi nilai-tanda dan nilai-simbol keislaman di tengah dominasi kartun sekuler. Menggunakan platform media baru seperti Youtube dan TV, animasi Nussa hadir untuk memenuhi kebutuhan pasar umat Muslim kelas menengah urban. Dua pertanyaan yang diajukan dalam artikel ini adalah: bagaimana media baru membuka kemungkinan representasi Islam? Dan, representasi Islam seperti apa yang dibawa animasi Nussa? Penulis menemukan bahwa demokratisasi media telah mendorong hadirnya suara-suara yang di masa sebelumnya ditekan dan bahkan direpresi oleh kekuasaan militeristik Soeharto. Islam adalah salah satunya. Di lain pihak, aspek keberagaman Islam itu sendiri menjadikan proses islamisasi lebih dinamis. Nussa hanyalah salah satu agen yang meramaikan kontestasi tersebut karena pada kenyataannya tidak ada satu pihak pun yang mengendalikan proses islamisasi di Indonesia. Sebagai konsekuensi, animasi Nussa tidak saja mendapat sambutan yang hangat dari sebagian umat Muslim, tetapi juga menerima tuduhan yang kurang menggembirakan dari umat Muslim lainnya.

Kata Kunci: religiotainment; Nussa; semiotika 


\section{LATAR BELAKANG}

Dalam sebuah esai berjudul Muslim Tanpa Masjid, Kuntowijoyo mensinyalir bahwa di akhir abad ke-20 telah lahir sebuah generasi baru Muslim yang kehadirannya tidak ditunggui oleh sang ayah, tidak pula disambut oleh saudara-saudaranya. Sebagaimana judul artikel tersebut, generasi baru ini bernama "Muslim Tanpa Masjid". Mereka terlibat aktif dalam aspirasi untuk mendefinisikan ulang arti menjadi Muslim, dan terlihat kontras dengan Muslim ideal yang direkomendasikan oleh otoritas keagamaan lama yang berada di lembagalembaga keagamaan mapan ataupun oleh elite politik. Lebih dari itu, pengetahuan agama mereka tidak berasal dari lembaga-lembaga Islam konvensional seperti masjid, pesantren, atau madrasah. Sebaliknya, majalahmajalah, radio, televisi, kaset VCD/DVD, dan internet adalah sumber-sumber utama dalam memenuhi kebutuhan religius mereka. Ini sekaligus menjelaskan bahwa 'jenis kelamin' generasi baru Muslim tersebut adalah kelas menengah perkotaan (Kuntowijoyo, 2019).

Rupanya, kasus Indonesia di atas tidak berdiri sendiri. Di tahun-tahun itu, atau sekitar akhir abad ke-20 dan awal abad ke-21, kebangkitan kelas menengah urban di kalangan umat Muslim merupakan fenomena global. Sejumlah pengamat menyebut jika hal itu adalah konsekuensi dari lonjakan kekayaan minyak bumi dan akses lebih besar pada pendidikan yang membawa perluasan dan konsolidasi politik dari apa yang disebut "kelas menengah perkotaan" (Heryanto, 2018). Pada gilirannya, keberadaan generasi Muslim baru tersebut menuntut adanya pemenuhan atas kebutuhan baru di ruang-ruang politik, ekonomi, kebudayaan, dan tentu saja agama. Gejala ini pernah dibahas oleh Asef Bayat (1996) sehubungan dengan kasus "ketakwaan post-islamisme" di Iran, Mesir, dan daerah-daerah lain di Timur Tengah pada tahun 2000-an.

Bayat mengawali analisanya lewat kebangkitan bintang dakwah televisi Mesir bernama Amr Khalid yang pada tahun 1999 menyampaikan sekitar 21 pelajaran setiap pekan di rumah-rumah keluarga terpandang dan mencapai puncaknya pada bulan Ramadhan dengan 99 pelajaran (Bayat, 1996). Ringkasnya, jika Mesir punya nama seperti Amr Khalid yang sengaja mengincar kaum muda dan perempuan di kelompok elite, maka Indonesia punya Aa Gym, Jeffry al-Buchori, Arifin Ilham, Mamah Dedeh, Ustadzah Oky, dan lain sebagainya. Mereka semua adalah pendakwah yang populer di televisi dan budaya layar lainnya. Oleh para peneliti, gejala tersebut diidentifikasi sebagai fenomena dakwahtainment (Fiardi, 2021; Saefulloh, 2009; Sofjan, 2012).

Dakwahtainment pada dasarnya hadir dalam rangka pemenuhan kebutuhan baru generasi Muslim urban. Di titik ini, televisi memainkan peranannya sebagai jembatan antara kepentingan industri yang berorientasi pada profit dengan keinginan pasar yang ingin belajar agama secara praktis. Alih-alih membatasi ruang gerak, jumlah frekuensi yang terbatas justru membuat industri televisi semakin gencar melakukan penetrasi ke dalam ruang privat masyarakat. Ketika dakwah keislaman berjabat-tangan dengan televisi, maka yang dibahas bukan lagi perkara hukum syariat, tetapi juga gaya hidup yang tercermin dari politik representasi para pendakwah (Hoesterey, 2008). Akibatnya, yang profan dengan yang sakral, yang etis dengan yang estetis, semuanya melebur ke dalam arus besar budaya populer.

Sementara dakwahtainment berorientasi di wilayah subjek-pendakwah, ada istilah lain yang memiliki konotasi lebih luas tapi masih beririsan, yaitu religiotainment. Kendati keduanya melayani ideologi yang sama (baca: kepentingan pasar), terdapat perbedaan signifikan antara religiotainment dengan dakwahtainment. Untuk kepentingan yang ringkas, izinkan saya menjelaskan perbedaan itu secara kasaran.

Fenomena dakwahtainment merupakan temuan mutakhir, seiring dengan cepatnya perkembangan teknologi pasca perang dunia II dan semangat post-islamisme di Indonesia yang tidak saja merangkak secara terus menerus ke dalam institusi-institusi politik, tetapi juga merangsek ke wilayah budaya populer (Heryanto, 2018). Walakin, selain kemajuan teknologi informasi, jatuhnya rezim militeristik Suharto pada tahun 1998 senyatanya turut membuka ruang bagi transmisi ajaran Islam, baik di masjid-masjid, maupun di wilayah media baru. Meruahnya dakwahtainment (Islamic Televangelism) ternayata berkait berkelindan dengan meningkatnya minat masyarakat Indonesia terhadap keberadaan dai televisi (Muzakki, 2012).

Dakwahtainment umumnya dimengerti sebagai perpaduan antara "dakwah" dengan "entertainment" atau hiburan (Fiardi, 2021; Saefulloh, 2009; Sofjan, 2012). Meski begitu, istilah dakwah sangatlah bias Islam. Dakwahtainment, dengan demikian, hanya berlaku untuk menelaah gejala sosial yang melibatkan subjekpendakwah, sehingga ia akan kesulitan untuk menjamah aspek yang lebih luas di wilayah budaya layar (screen culture) atau budaya populer lainnya.

Di lain pihak, saya pertama kali menemukan istilah religiotainment ketika membaca artikel Wisnu Prasetya Utomo berjudul Ramadhan, Televisi, dan Kelesuan Rohani. Di sana, Utomo menyoal tayangan-tayangan televisi di bulan Ramadhan yang umumnya bertopeng agama, tetapi justru miskin makna. Tayangan-tayangan itu antara lain adalah Sahurnya Fesbuker (ANTV), Yuk Kita Sahur (Trans TV), dan termasuk tayangan yang banyak disebut sebagai produk berkualitas, Hafidz Indonesia (RCTI). Praktis, religiotainment di sini berarti fusi antara agama (religion) dengan hiburan (entertainment) yang (di)hadir(kan) di media baru (Utomo, 2013). 
Berangkat dari alasan tersebut, artikel ini lebih mempertimbangkan religiotainment sebagai duduk perkara (subject matter) untuk mendiskusikan persoalan yang cukup kompleks di ruang serba media. Adapun kajiankajian yang pernah membahas topik religiotainment sebetulnya sudah cukup melimpah, kendati tidak harus melibatkan istilah tersebut secara tegas. Ini bisa kita jumpai lewat sedikitnya dua penelitian: pertama, riset Remotivi berjudul Perempuan Tanpa Otonomi: Wajah Ideologi Dominan dalam Sinetron Ramadhan (Thaniago \& Arief, 2014). Penelitian tersebut melokalisir masalah pada sinetron yang tayang pada Ramadhan 2013. Tiga stasiun televisi dan judul sinetron yang menjadi objek pengamatan adalah Anak-anak Manusia (RCTI), Para Pencari Tuhan 7 (SCTV), dan Hanya Tuhanlah yang Tahu (Trans TV). Kedua, riset yang beririsan dengan fenomena religiotainment bisa kita temui lewat buku Ariel Heryanto berjudul Identitas dan Kenikmatan (2018). Di sana, Heryanto mendedah secara detail pertempuran sinematis yang melibatkan nilai-simbol keagamaan. Film-film yang menjadi bidikan Heryanto meliputi Ayat-Ayat Cinta (Bramantyo, 2008), Perempuan Berkalung Sorban (Bramantyo, 2009), Ketika Cinta Bertasbih (Chaerul Umam, 2009), Kiamat Sudah Dekat (Deddy Mizwar, 2003), dan Catatan Si Boy (Nasri Cheppy, 1987) (Heryanto, 2018).

Satu pendapat pokok yang diajukan dalam artikel ini adalah baik dakwahtainment maupun religiotainment sama-sama membawa misi ideologis serupa, yaitu islamisasi di wilayah budaya populer. Alih-alih sebagai proyek politis, islamisasi di sini mengacu pada apa yang disebut oleh Heryanto sebagai sebuah proses yang kompleks dan beragam, melibatkan berbagai kelompok umat Muslim yang pada kenyataannya memang tidak pernah seragam dan belum tentu saling setuju satu sama lain. Ciri utama adanya beragam proses islamisasi ini adalah terjadinya perluasan cara pandang, penampilan, dan gaya hidup yang mafhum dipahami oleh masyarakat Indonesia sebagai mengandung nilai-nilai islami atau "yang terislamkan" (Heryanto, 2018).

Untuk mendiskusikan adanya proses islamisasi di wilayah budaya populer tersebut, saya menggunakan animasi Nussa Rara (selanjutnya disebut animasi Nussa). Sebagai ilustrasi ringkas, animasi Nussa besar kemungkinan akan kesulitan mendapat panggung jika ia diproduksi dan ditayangkan di masa pemerintahan Soeharto. Tapi situasi hari ini senyatanya telah berbeda. Standar kepatutan politik saat ini telah memungkinkan Islam, baik sebagai diskursus maupun kelompok, tampil dengan terang-terangan. Maka, produksi film yang (sengaja) menjadikan tema keagamaan, Islam khususnya, tampak melimpah, tidak saja di layar lebar, tetapi juga di televisi seperti tayangan "Azab" atau "Dzalim" yang menglorifikasi kekejaman Tuhan, meski dalam wujud paling absurd (Heychael, 2018).

Sehubungan dengan islamisasi mutakhir di wilayah budaya populer, kecenderungan norma dominan yang berlaku saat ini mendedah dirinya dalam frasa "subjek Islam/Muslim sebagai problem solver" atau minimal sebagai pusat dari narasi. Ini, misalnya, bisa kita lihat dari film Nussa (2021). Di sana, tampak jelas plot twist yang memposisikan karakter Nussa sebagai tokoh ideal (anak-anak) Muslim yang inspiratif, saleh, dan cerdas, namun sekaligus tak luput dari kenakalan khas bocah seumurannya. Logika serupa juga tertuang secara benderang dalam film Ayat-ayat Cinta (2008) yang produksinya oleh para akademisi dianggap sebagai titik balik hadirnya budaya populer Islam di dalam film. Meski begitu, film Ayat-ayat Cinta rupanya bukanlah pelopor awal di Indonesia pasca kemerdekaan Indonesia. Jumhur pengamat menyebut bilamana kebangkitan Rhoma Irama sebagai "Raja Dangdut" pada dekade 1970-an adalah pelopor paling penting dalam kemunculan budaya populer islami (Heryanto, 2018).

Di atas itu semua, penggunaan animasi Nussa dalam artikel ini adalah karena dua alasan. Pertama, animasi Nussa adalah fragmen baru di wilayah religiotainment yang, sekali lagi, meskipun sudah banyak kajian tentang religiotainment, kajian kritis yang berfokus terhadap animasi rupanya masih sedikit. Kedua, animasi Nussa hadir di tengah dominasi kartun sekuler di wilayah budaya layar. Di titik ini, kita sebetulnya bisa membandingkan animasi Nussa dengan pendahulunya, yaitu animasi Upin Ipin. Diferensiasi kedua animasi tersebut menjadi menarik untuk dicermati. Sementara animasi Nussa secara tegas mengadopsi nilai-tanda dan nilai-simbol keislaman, animasi Upin Ipin justru melihatkan sisi kontras, yaitu representasi (moral) Islam di dalamnya hadir secara informal dan kultural tanpa harus membranding Upin Ipin sebagai animasi islami. Kendati demikian, baik animasi Nussa maupun Upin Ipin secara konsisten mulai meruntuhkan dominasi kartun Jepang. Jika Upin Ipin mampu menggaet jumlah penonton dengan prosentase lebih besar ketimbang kartun Jepang lainnya (Nuswantoro, 2012), maka animasi Nussa mulai merambah ke wilayah internasional setelah memiliki basis yang cukup kuat di Indonesia dan mendapat ruang tayang di Bucheon International Fantastic Film Festival (BIFAN) pada Juli 2021 lalu (Yuniar, 2021).

\section{METODE}

Penelitian ini adalah jenis penelitian kualitatif. Objek material dari penelitian ini berupa animasi Nussa, sedangkan objek formalnya meliputi konsep literasi dan semiotika media milik Elliot Gaines (2010). Sumber data artikel ini diperoleh dari Channel Youtube Nussa Official dan/atau stasiun televisi yang sempat menyiarkan 
animasi tersebut. Data yang terkumpul kemudian diperiksa menggunakan perangkat analisis semiologi untuk meninjau budaya, ideologi, dan mitos-mitos (dalam pengertian Roland Barthes) yang diproduksi oleh animasi Nussa, yang darinya memunculkan beragam resepsi dari masyarakat dan pengamat media.

Di sini, kata "budaya" (culture) mengacu pada sekelompok orang yang berbagi nilai-nilai, kepercayaan, dan laku keseharian. Sebuah budaya di satu daerah bisa saja berbeda dengan budaya di daerah yang lain karena anggota dari suatu masyarakat yang berbeda akan memahami suatu tanda secara berbeda pula. Nilai, keyakinan, dan gagasan ideal yang membentuk cara orang bertindak ini disebut ideologi (ideology). Sementara itu, hal-hal yang membentuk ideologi dan budaya kebanyakan dipandu oleh mitos (myth), sistem representasi konotatif yang menyiratkan pemahaman yang samar berdasarkan praktik dan cerita masa lalu yang tidak didukung oleh bukti substansial yang dapat diverifikasi. Di lain pihak, mitologi merepresentasikan sistem kolektif dari perspektif interpretatif, termasuk ideologi yang sering dibagikan dan diperdebatkan dalam suatu budaya. Di luar gairah budaya yang berbeda dan ideologi serta mitos dari berbagai kelompok kepentingan, metode semiotik dapat menginformasikan wacana sosial dengan memberikan kriteria yang jelas untuk analisis kritis terhadap aspek media yang dapat diamati (Gaines, 2010).

Sederhananya, fungsi dari perangkat semiologi tidak saja menggambarkan bagaimana tanda mewakili makna, tetapi juga

merupakan alat untuk menggugat keyakinan dan praktik-praktik yang telah dianggap mapan agar membuat orang tidak terlalu nyaman dengan asumsi mereka sendiri tentang apa yang tampak normal, karena apa yang mereka yakini sebagai benar atau nyata tidaklah selamanya begitu. Jadi, sebuah tanda harus berada dalam hubungannya dengan tanda lain dalam konteks tertentu.

Tokoh-tokoh dalam sebuah cerita dipahami menurut kode-kode, sebagaimana pengertian keluarga menyiratkan relasi tertentu antara suami dan istri, orang tua dan anak, dan masyarakat tempat mereka berinteraksi. Bahasa, suara, dan gambar pastilah mengikuti struktur dan aturan yang rumit untuk membangun makna melalui cerita. Analisis struktur dan proses komunikasi mengungkapkan asumsi yang terkadang memancing pertanyaan yang layak tentang keyakinan dan praktik yang digambarkan di media. Untuk penjelasan yang singkat, izinkan saya mendeskripsikan secara padat terkait beberapa perangkat semiotik terapan yang akan digunakan dalam proses analisis animasi Nussa.

Semiotika menyediakan banyak alat yang dapat disesuaikan dengan kekhususan artefak media dan dapat membantu membangun pemahaman tentang proses yang mengkonstruksi makna. Alat-alat itu berfungsi dengan menggambarkan bagaimana tanda mewakili makna, sehingga pengamat yang kritis dapat melihat sekaligus melampaui isi dan makna yang dimaksudkan dari sebuah teks untuk memeriksa struktur dan proses yang digunakan untuk berkomunikasi. Di saat yang sama, fungsi tanda adalah untuk mewakili makna, dan ini dicapai dalam banyak cara. Karakteristik tanda yang paling konsisten adalah tanda itu menandakan, mengungkapkan, atau mewakili sesuatu. Meski begitu, tanda bukanlah hal yang diwakilinya; tanda adalah ekspresi dari makna atau objek yang diwakilinya. Untuk itu, ada dua istilah penting dalam semiotika, yaitu penanda (signifier) dan petanda (signified). Penanda dipahami sebagai ekspresi atau representasi dari suatu objek/makna yang disebut petanda. Sementara itu, petanda (objek atau makna) dipahami sebagai aspek mental yang mengandung makna denotatif (eksplisit) dan makna konotatif (tersirat). Kedua makna tersebut mencerminkan beberapa konteks sosial untuk kepentingan proses interpretasi (Gaines, 2010).

Nussa, Rara, Umma, dan Tante Dewi adalah sejumlah karakter yang kerap muncul di animasi Nussa. Sebagai sebuah genre, animasi Nussa merupakan tontonan berisi drama edukatif keluarga yang keberadaannya dimaksudkan untuk menyasar kalangan anak-anak atau keluarga Muslim pada umumnya (Nussa Official Youtube Channel, 2018). Hingga artikel ini dibuat, kanal Youtube Nussa Official memiliki 8.28 juta subscribers, sejak pertama kali rilis pada 20 November 2018. Jika melihat data pengguna internet aktif di Indonesia, pengikut animasi Nussa tersebut memang terhitung sedikit, 8.28 juta dari 181.9 juta populasi pengguna internet aktif (Lidwina, 2021). Meski begitu, animasi Nussa senyatanya pernah sedikitnya dua kali mewarnai percakapan publik di media sosial (Hastanto, 2021; Kurniawan, 2021; Supriansyah, 2020).

Mafhumnya budaya layar, animasi Nussa memadukan hal-hal kompleks antara kode estetika, naratif, visual, verbal, dan ideologis yang bekerja di dalamnya. Animasi seperti Nussa digambar atau dikondisikan agar menyerupai karakteristik umum manusia. Kendati karakter-karakter yang ada di dalam animasi hanyalah fiktif, tetapi narasi di dalamnya menggunakan struktur, pengaturan latar, dan institusi sosial yang realistis. Dengan kata lain, setiap karakter adalah tanda bagi peran gender dan keluarga yang dimainkan dalam kaitannya dengan sistem sosial yang menentukan perilaku.

Lebih dari itu, sebagai bagian dari sistem representasi di ruang serba media, animasi Nussa seharusnya tidak dianggap sebagai hiburan belaka, utamanya ketika ia telah menjadi program TV di bulan Ramadhan dan di jam-jam krusial (prime time). Di sini, hadirnya animasi Nussa bisa dibaca sebagai pemenuhan kebutuhan 
emosional (pleasure) oleh industri media melalui sebuah ideologi mass culture. Maka, sebuah episode dari animasi Nussa akan ditelaah sebagai teks budaya (layar) populer dengan melihat lebih dekat konstruksi identitas serta sirkulasi ide dan nilai yang disajikan sebagai hiburan. Sebagai bagian dari budaya, animasi Nussa mencerminkan mapannya karakter dalam program yang mengandung praktik representasi usia, gender, dan kelas, dan didorong oleh asumsi budaya dan mitologi.

Representasi media tentang karakter dan situasi cenderung memengaruhi kesadaran penonton, bahkan jika dibesar-besarkan dan tidak akurat. Analisis tidak dimaksudkan sebagai penghakiman norma dan tidak dimaksudkan untuk memaklumi atau mengutuk program atau tontonan tersebut. Sebaliknya, analisis semiotik media ini dimaksudkan untuk menyediakan data empiris yang menginformasikan wacana sosial dan meningkatkan tingkat literasi media. Literasi media mempromosikan pemikiran kritis yang dapat membantu audiens agar lebih sadar tentang bagaimana memahami secara lebih baik isi media secara teknik produksi, generalisasi tentang nilai-nilai, keyakinan, dan stereotip, dan dampak potensial dari representasi tersebut pada cara masyarakat menegosiasikan pengertian media (Gaines, 2010).

\section{HASIL DAN PEMBAHASAN}

\section{Media Baru dan Representasi Islam}

Sejak pertama kali tayang di Youtube animasi Nussa telah mendapat sorotan publik, baik yang berbentuk apresiasi maupun kontroversi. Tingginya fragmentasi umat Islam di Indonesia mendorong munculnya berbagai tafsir tentang animasi tersebut. Animasi yang bisa dibilang menyejukkan secara visual dan secara pengisian suara ini menjadi 'bola panas' di media sosial. Seorang pegiat media sosial, Eko Kuntadhi (2021), misalnya, dalam sebuah cuitan di Twitter menuduh animasi Nussa sebagai cerminan sekelompok ekstremis di Afghanistan, Taliban. Bagi Eko, gamis yang menjadi dresscode Nussa bukan lumrahnya pakaian anak Indonesia. Sebelumnya, hal serupa pernah didengungkan oleh akun twitter Denny Siregar. Denny menilai bahwa animasi Nussa Rara mengandung agenda politik khilafah HTI. Alasannya, Felix Siauw (salah satu tokoh HTI) diduga terlibat dalam proses produksi animasi tersebut. Tak butuh waktu lama, tuduhan itu mendapat balasan yang tak kalah pedas dari warganet Indonesia. Oleh pendukungnya, animasi Nussa disebut sebagai tontonan yang mempromosikan semangat nasionalisme dengan episode berjudul "Hari Kemerdekaan RI" sebagai buktinya. Tak ketinggalan, pihak produser dan animator juga secara tegas menyatakan bahwa animasi Nussa Rara terbebas dari agenda politik kelompok manapun (Zuhad, 2021).

Betapapun, animasi Nussa memang cukup menonjolkan nilai-simbol keislaman. Ini bisa kita dapati secara mudah jika merujuk langsung ke kanal Youtube Nussa Official. Satu episode yang telah dibahas di bagian sebelumnya dalam artikel ini menunjukkan betapa animasi Nussa sangat berkelindan dengan tren dan/atau konteks di mana tontonan tersebut dibuat: bahwa proses islamisasi di wilayah budaya populer hadir penuh kejutan, tantangan, sekaligus kontestasi berbagai kelompok yang berbeda dan belum tentu saling setuju. Proses islamisasi tersebut kemudian disebut religiotainment, gabungan antara tontonan religius dengan logika hiburan. Apalagi jika mengingat bahwa animasi Nussa menyeruak di tengah kosongnya pasar 'kartun Islami' di Indonesia, maka ia seolah dapat menenangkan para orang tua Muslim yang khawatir kalau anaknya tak kebagian jatah tontonan sehat ketika menyalakan TV atau mengakses Youtube.

Kartun adalah segmen tontonan yang identik dengan anak-anak, dan pada derajat tertentu menjadi konsumsi orang dewasa. Di Indonesia, kebutuhan terhadap tayangan kartun utamanya diisi oleh kartun Jepang dan Amerika, seperti Doraemon, Ninja Hatori, One Piece, Spongebob Squarepants, Hey Arnold, wa akhwatuha. Ringkasnya, Jepang dan Amerika setidaknya telah mengisi kebutuhan kartun di Indonesia sejak dekade 90-an hingga kini. Baru di tahun 2009, serial kartun dari negara tetangga, Malaysia, berjudul Upin Ipin muncul perdana di TPI dan langsung mendapat sambutan hangat dari pemirsa Indonesia. Alasan yang patut diduga adalah karena Upin Ipin menyajikan kedekatan budaya, agama dan nilai pergaulan. Di animasi Upin Ipin, adalah pertama kali bagi pemirsa Indonesia menyaksikan scene perayaan hari Lebaran dalam bentuk visualitas kartun, sesuatu yang tentu saja absen di kartun Jepang dan Amerika. Lebih dari itu, adegan kejar-kejaran dengan ayam kampung, representasi kulit kuning atau sawo matang, pengenaan baju takwa, peci, hijab, dan sejenisnya, adalah senarai kenikmatan visual yang mustahil pemirsa Indonesia dapatkan di kartun Jepang dan Amerika-yang umumnya menyajikan kimono, kuil, adu jurus, orang kulit hitam, rusa, pohon cemara, natal, bikini, hubungan heteroseksual dan individualisme. Dengan kata lain, Upin Ipin adalah 'respirator' pertama yang memberikan kelegaan nafas bagi orang tua Indonesia yang anaknya sehari-hari dijejal nilai-nilai Barat dan Timur Jauh (Haq, n.d.). Jadi, ada semacam rasa aman tersendiri atas hadirnya suguhan narasi melayu, Islam dan Asia Tenggara. Di titik ini, kehadiran animasi Nussa Rara membuat orang tua Muslim masa kini tidak lagi perlu merasa khawatir: apakah anaknya akan meniru Tuan Crab si Kapitalis, atau ilmuan sekuler yang suka membuka aurat ala Sandy si Tupai, 
kemudian pemberontak seperti Monkey D. Luffy, siswa bucin yang malas belajar seperti Nobita, ataupun meniru pelaku genosida seperti Uchiha Itachi.

Patut digaris-bawahi di sini adalah kehadiran animasi Nussa ternyata memanfaatkan platform media sosial seperti Youtube dan baru mengudara di televisi setelah mendapat pengakuan publik. Itu pun terjadi setahun setelah tayang pertama di Youtube pada tahun 2018 dan baru dipinang televisi (Net TV) tahun 2019 untuk memenuhi kebutuhan konsumsi tontonan di bulan Ramadhan. Fakta ini agak kontras dengan kartunkartun (pendahulu) lainnya yang medium pesebarannya adalah lewat televisi terlebih dahulu dan baru merambah Youtube belakangan.

Praktis, ontran-ontran tafsir yang menyelimuti perjalananan animasi Nussa relatif lebih beragam ketimbang kartun lainnya. Ada sedikitnya dua alasan. Pertama, representasi Islam yang dibawa animasi Nussa cukup segmented, yaitu khas kebutuhan masyarakat Muslim kota yang berfokus pada kesalehan ritual di tengah bejibun rutinitas pekerjaan dan sekolah. Maka, wajar saja jika dari segenap episode yang pernah tayang baik di Youtube maupun di televisi, animasi Nussa tidak merasa perlu untuk mengakomodasi praksis sosial Muslim tradisional seperti tahlilan, hadrah, dan ritual-ritual asimilasi lainnya. Kedua, kekuatan dari media baru memungkinkan percakapan antar subjek menjadi lebih cair dan karena itu kadar keterjangkauannya pun menjadi lebih lebar. Asumsinya adalah tidak setiap orang mengakses televisi, tetapi nyaris setiap orang memiliki perangkat yang membuatnya terhubung dengan dunia di luar dirinya. Maka, orang mempercakapkan animasi Nussa kendati belum pernah menonton animasi tersebut. Di titik ini, orang jadi punya kecenderungan baru: yang penting adalah ikut komentar dan terlihat eksis di media baru dengan cara update informasi. Itulah yang terjadi dengan akun twitter Denny Siregar maupun Eko Kuntadhi.

\section{Sebuah Proses Memberi Makna}

Analisis semiotik berikut mencakup deskripsi teks berupa dialog, suara, dan gambar dari episode "Bukan Mahram" dalam animasi Nussa yang rilis pada 3 Mei 2019 dan menjadi salah satu episode yang tayang di televisi medio 2020 pada bulan Ramadhan. Diskusi ini terbatas pada tanda dan sistem tanda yang relevan dengan analisis, sehingga aspek-aspek tertentu dari program akan dibahas lebih rinci daripada yang lain. Setiap detail tidak diperlukan untuk analisis yang efektif, tetapi urutan adegan demi adegan yang sebenarnya dari pertunjukan membantu untuk menunjukkan perkembangan naratif dan fungsi peristiwa, lokasi, dan karakter cerita.

Ketika menonton hiburan, orang umumnya akan menangguhkan ketidakpercayaan mereka untuk sekadar menikmati pengalaman. Sebaliknya, seorang analis kritis ingin mengenali nilai dan asumsi yang tertanam dalam artefak media dan karena itu harus mengidentifikasi proses kreatif dan sifat media. Para penulis dan produser hiburan naratif seperti animasi Nussa berfokus dengan menarik penonton lewat karakter dari kehidupan nyata yang digeneralisasi. Animasi Nussa menjadi menarik bagi penonton karena situasinya cukup otentik untuk menimbulkan pertanyaan tentang nilai, keyakinan, dan praktik representasi. Penonton mengidentifikasi karakter dan situasi yang memancing penyelesaian dilema dalam proses bercerita. Dalam kasus ini, masalah prinsipnya adalah Nussa menolak berjabat tangan dengan Tante Dewi karena dianggap bukan mahram (the other). Lebih detail, izinkan saya mendiskripsikan babak demi babak secara ringkas dan semoga jelas.

Episode "Bukan Mahram" terbagi menjadi lima babak (scenes). Pada babak pertama (opening sequence), episode "Bukan Mahram" dibuka dengan advetorial Bukalapak, perusahaan jual beli online yang cukup populer di Indonesia. Di bawah logo Bukalapak ada keterangan berbunyi "Mendukung Kreativitas Anak Bangsa". Ini semakin menegaskan bahwa animasi Nussa merupakan produk kawula muda Indonesia yang bergerak di bidang budaya layar, berjibaku dengan dominasi kartun sekuler (Oktafiani, 2018). Adegan kemudian memotong ke (siluet) aksi Nussa yang melambaikan tangan.

Babak selanjutnya (scene ke-dua) adalah perkenalan karakter. Kamera menyorot sosok perempuan yang sedang menyapu lantai rumah. Sejurus kemudian, ada suara dari luar rumah berbunyi "assalamualaikum", petanda bahwa ada tamu. Setelah pintu dibuka, keduanya lalu bertegur sapa secara akrab. Perempuan yang menyapu adalah Umma dan sosok yang bertamu adalah Tante Dewi, adik perempuan Umma. Yang menarik adalah percakapan antara Umma dengan Tante Dewi. Berikut dialog verbatimnya:

$\begin{array}{ll}\text { Umma } & : \text { "Kamu gimana kabarnya?" } \\ \text { Tante Dewi } & \begin{array}{l}\text { "Alhamdulillah baik Kak. ya gini lah kalo jadi PNS, harus siap ditugaskan ke pelosok- } \\ \text { pelosok tanah air." }\end{array} \\ \text { Umma } & : \text { "...Kakak salut sama kamu, Allah kabulkan cita-cita muliamu sebagai guru." }\end{array}$


Di sini, ada sedikitnya tiga fragmen penting sehubungan dengan mitos di balik adegan tersebut. Pertama, sorot kamera yang memposisikan perempuan identik dengan tugas rumahan; kedua, karir Tante Dewi sebagai PNS; dan ketiga, profesi guru yang dilekatkan pada (kemuliaan) sosok perempuan. Dengan kata lain, ada selubung ideologi yang hendak disampaikan: perempuan sebagai gender yang masih tersubordniasi oleh sistem patriarkhi. Di sisi lain, hadirnya "PNS" sebagai pilihan karir Tante Dewi menjelaskan identitas sosialnya, yaitu masyarakat kelas menengah Muslim. Klaim ini berdasarkan upah rata-rata untuk mengkonsumsi gaya hidup kelas menengah yang setara dengan Rp. 3,752 juta per bulan (Riswan, 2021). Sementara itu, jika melihat ratarata gaji pokok guru PNS adalah senilai 2-4 juta rupiah per bulan (Idris, 2020).

Selanjutnya, Tante Dewi menyapa Rara lalu menghampirinya. Sementara keduanya terlibat dalam hangatnya bertegur-sapa, Nussa merangsek masuk ke rumah. Menariknya, adegan dibikin cukup halus karena kehadiran Nussa adalah persis setelah Tante Dewi menanyakan keberadaan si karakter utama, "eh, ngomongngomong Kakak Nussa mana ya?"

Di titik inilah konflik dalam plot cerita bermula. Dalam adegan, sorot kamera secara jelas membidik penolakan Nussa terhadap upaya Tante Dewi ketika mengajak berjabat tangan. Tapi hal itu akan kita diskusikan lebih jauh pada bahasan di scene selanjutnya. Sekarang, saya ingin menunjukkan satu bagian penting dari dialog Tante Dewi dan kesan pertama Nussa.

Tante Dewi :"Kamu pasti baru pulang ngaji kan? MasyaAllah solehnya anak ini. Ini Pasti Hafalannya sudah banyak sekali, sudah sampai juz berapa coba?"

Nussa : (dalam hati): "Ini siapa ya? Kok Nussa lupa ya."

Apa yang menjadi ekspresi dari karakter Tante Dewi di atas mencerminkan watak zaman dan latar tempat di mana animasi itu berada, yaitu angan-angan terhadap sosok ideal Muslim kanak-kanak hari ini yang belajar mengaji ke surau atau masjid, menghafal Qur'an, dan tentu saja saleh perangainya. Tren anak-anak menghafal Qur'an ini bahkan sempat menjadi industri tontonan di belahan stasiun televisi lainnya. Bertajuk "Hafiz Indonesia", program televisi tersebut diklaim pernah mendapat rating share yang tinggi (Kutanto, 2017).

Babak kemudian berlanjut di scene ke-tiga. Ini ditandai oleh ajakan Umma agar mereka segera bergegas ke ruang makan. Di ruang makan, Nussa terlibat dialog dengan Rara. Rara menyoal kenapa Nussa tidak menyalami Tante Dewi. Nussa tetap bergeming dengan prinsipnya, yaitu larangan menjalin kontak fisik dengan mereka yang bukan mahram (the others).

$\begin{array}{ll}\text { Rara } & \text { : "Tadi kenapa (Kak Nussa) gak salim sama Tante Dewi?" } \\ \text { Nussa } & : \text { "Salam? Kan bukan Muhrim." }\end{array}$

Adegan kemudian beralih ke sosok Umma yang dari belakang mematahkan asumsi Nussa.

Umma : "Maksudnya mahram kali... Kalo muhrim, artinya orang yang pake baju ihram. Kalo mahram, orang-orang yang gak boleh dinikahi karena masih ada hubungan keluarga, pernikahan, atau persusuan."

Nussa : "lya, maksudnya bukan mahram, soalnya Pak Ustadz ngingetin kalau kita gak boleh salaman dengan yang bukan mahram."

Di bagian ini, ada sedikitnya tiga hal yang layak kita catat. Pertama, konsep mahram dan muhrim seringkali dipahami secara terbolak-balik. Apa yang tercermin dalam adegan di atas seolah mewakili realitas sosial yang ada, di mana umat Muslim terkadang latah membedakan konsep mahram dan muhrim. Kedua, adegan tersebut menunjukkan proses transmisi ilmu dalam tradisi kebanyakan umat Muslim dan menjelaskan seberapa signifikan kapital intelektual seseorang membentuk habitus orang yang bersangkutan. Ketiga, konsep mahram dalam praksis sosial seringkali dipakai untuk mengeksklusi liyan. Pangkal masalahnya adalah terletak pada anggapan terhadap status haram ketika laki-laki berkontak fisik dengan perempuan, atau sebaliknya, dalam kondisi sadar. Meski begitu, status keharaman tersebut ternyata tidaklah mutlak. Dengan kata lain, ada sejumlah ulama yang tetap membolehkan hal itu terjadi (Idris, 2020; Kurniawan, 2018). Hanya saja, pluralitas pendapat itu rupanya absen-atau malah sengaja dihilangkan-dari episode "Bukan Mahram" dalam animasi Nussa. Lebih dari itu, status keharaman bersentuhan fisik dengan mereka yang bukan mahram tersebut tampak semakin diglorifikasi ketika penutup episode ini (closing sequence) menampilkan quote berbunyi: Kenali Mahram Kita Agar Selamat Dunia dan Akhirat. 


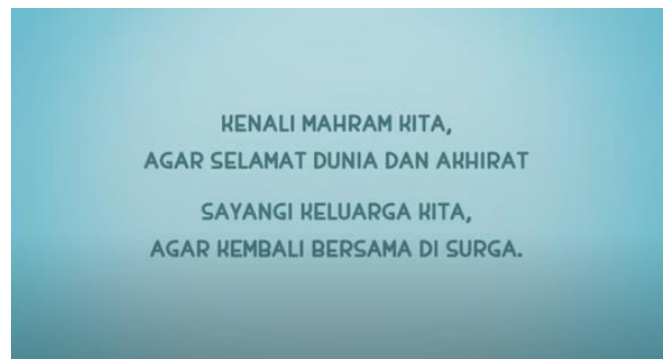

Gambar 1. Scene yang Menampilkan Quote: Kenali Mahram Kita Agar Selamat Dunia dan Akhirat

Teks di atas tentu saja menarik jika dibaca lewat kacamata politik representasi. Untuk kepentingan ini, saya meminjam sedikit konsep dari Stuart Hall yang dia tuangkan dalam buku The Work of Representation. Hall mendefinisikan representasi sebagai "the production of the meaning of the concepts in our minds through language" (Hall, 1997). Terapan dari konsep Hall ini bisa kita temui, misalnya, dalam pemberitaan media ketika merepresentasikan bencana dalam liputannya. Bencana tidak dengan sendirinya memiliki makna yang bersifat tetap atau final. Sebaliknya, bencana baru memiliki makna setelah termediasi atau ketika direpresentasikan dalam bentuk berita televisi, citra visual fotografi, atau bentuk mediatisasi lainnya. Ketika bencana dihadirkan kembali di layer televisi, makna-makna tertentu tentangnya dibangun dan diproduksi, baik oleh produsen maupun audiens. Tak kalah penting, makna bencana yang dihadirkan kembali di televisi bisa jadi berbeda dengan makna yang dihadirkan dalam fotografi atau dalam film documenter, karena tidak ada true meaning yang melekat pada bencana (Noviani, 2020). Dengan definisi tersebut, Hall sebenarnya sedang mengkritik pemahaman yang menyebut bahwa representasi sekadar menangkap dan menampilkan kembali makna-makna yang sudah ada sebelumnya. Pemahaman seperti ini secara ironis meyakini bahwa sesuatu (objek, peristiwa, orang) memiliki true meaning yang stabil, tak pernah berubah dan bersifat final.

Seperti terlihat pada Gambar 1 di atas, terdapat senarai kata yang berbunyi "Kenali Mahram Kita Agar Selamat Dunia dan Akhirat". Di sini kita bisa mengajukan beberapa pertanyaan kritis yang relevan untuk mengkaji teks representasi. Pertanyaan-pertanyaan itu meliputi: Siapa yang sedang berbicara dalam/melalui teks tersebut? Siapa yang berbicara di dalam teks dan yang berbicara melalui teks bisa saja sama bisa juga berbeda. Jawaban tentang siapa yang berbicara melalui dan di dalam teks akan memungkinkan kita untuk mengkaji kepentingan ideologis yang beroperasi melalui dan di dalam teks representasi tersebut.

Pada Gambar 1, semua pihak yang terlibat, baik karakter-karakter yang ada di dalam animasi maupun tim kreatif dan sang produser adalah sah disebut sebagai subjek yang berbicara. Tapi untuk kepentingan yang ringkas, mari kita berasumsi bahwa Pak Ustadz yang sempat Nussa mention di salah satu plot cerita adalah subjek yang sedang berbicara dalam teks tersebut. Alasannya, Pak Ustadz merupakan (salah satu) pihak yang membentuk dan mempengaruhi habitus Nussa, sehingga membuatnya enggan berjabat tangan dengan Tante Dewi karena dianggap bukan mahram. Jika dikaitkan dengan media yang memuat teks tersebut, yaitu closing sequence dalam film pendek di Youtube, kita bisa mengidentifikasi kuatnya konteks konservatisme beragama di dalam teks representasi, yang berkutat di wilayah hitam-putih hukum Islam (Alvara Research Center, 2019; Supriansyah, 2020).

Selanjutnya, kita bisa bertanya tentang siapa/apa yang dibicarakan dalam teks representasi dalam Gambar 1. Pertanyaan ini membantu kita untuk mengetahui bahwa teks tersebut sebetulnya sedang membahas apa/siapa. Teks pada Gambar 1 merupakan bentuk persuasi. Karena bersifat persuasif, berarti audiens diandaikan berada dalam posisi tak berdaya. Pola komunikasinya pun terkesan top-down. Apalagi jika mempertimbangkan bahwa animasi Nussa memang dimaksudkan sebagai medium edukasi untuk keluarga Muslim yang watak transmisi keilmuannya mulai bergantung pada teknologi, sehingga memungkinkan penetrasi nilai-nilai keagamaan merangsek sampai ke ruang yang paling privat.

Sebagai tambahan, sebelum beranjak ke closing sequence, episode "Bukan Mahram" dipungkasi dengan adegan swafoto. Dalam logika babak (scene), adegan itu masuk dalam scene ke-empat. Ceritanya, setelah Umma memberi keterangan bahwa Tante Dewi adalah mahram bagi Nussa, mereka berempat (Tante Dewi, Nussa, Rara, dan Umma) melakukan swafoto bersama. Khas tren peradaban pasca modern, mengabadikan kehangatan momen lewat foto bersama adalah perilaku umum. Jadi, ada tontonan di dalam tontonan. 


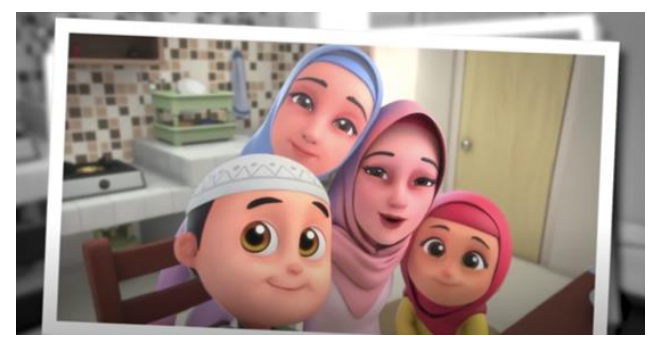

Gambar 2. Scene Tante Dewi, Nussa, Rara, dan Umma Melakukan Swafoto Bersama

Bicara tentang tontonan, seorang pemikir dari Prancis, Guy Debord, pernah menulis fenomena saling tonton ini dalam buku The Society of Spectacle. Dalam tesis keempatnya, Debord menulis bahwa "the Spectacle is not a collection of images, but a social relation among people, mediated by images" (Spectacle bukanlah kumpulan citra, tetapi relasi sosial antar manusia yang telah termediasi lewat gambar) (Debord, n.d.). Spectacle atau tontonan, dengan demikian, secara aktif menggubah interaksi dan relasi manusia. Citra/gambar mempengaruhi kehidupan dan keyakinan orang setiap hari, iklan menghasilkan hasrat dan aspirasi baru, sedangkan media menafsir (atau malah mereduksi) realitas dengan seperangkat narasi yang sederhana. Fotografi dan film, misalnya, mampu menerabas batas jarak dan waktu, menyajikan konektivitas universal. Produk-produk baru teknologi pun mengubah cara hidup kita.

Rupanya, gagasan Debord di atas dapat kita pakai untuk melihat situasi kiwari, khususnya ketergantungan kita pada teknologi. Apa yang Anda lakukan saat tersesat di kota asing? Apakah Anda menanyakan arah kepada orang yang lewat, atau berkonsultasi dengan Google Maps di ponsel cerdas Anda? Mungkin Siri bisa membantu. Teknologi semacam itu sangat berguna, tetapi juga merekayasa perilaku kita. Lebih dari itu, teknologi telah mereduksi kehidupan kita ke dalam suatu rangkaian pertukaran komoditas harian (Morgan \& Purje Lauren, 2016).

Adegan yang terlampir dalam Gambar 2 menunjukkan bahwa animasi Nussa mengakomodasi logika spectacle. Meski begitu, adegan ini justru seolah menegaskan bahwa animasi Nussa mewakili generasi baru dan terdidik Muslim yang tetap dapat menikmati selera kebudayaan mereka tanpa harus menanggalkan kehormatan diri atau mengorbankan keimanan. Malahan, secara umum banyak dari kaum Muslim kaya baru ini secara terang-terangan menampilkan hasrat yang besar terhadap hal-hal yang berkilauan dari dunia kapitalisme industrial yang secara benderang tidak islami (Heryanto, 2018). Logika seperti ini tentu saja kontras dengan salah satu diskursus keislaman yang mengklaim bahwa perempuan adalah haram melakukan swafoto karena dugaan menimbulkan fitnah bagi laki-laki yang melihatnya (Purnama, 2018). Jadi, ikhtiar Tante Dewi untuk mengajak Nussa, Rara, dan Umma berswafoto menjelaskan klimaks dari episode "Bukan Mahram", yaitu: idealisasi keluarga (kelas menengah) Muslim yang bahagia, penuh ketakwaan, sekaligus kekinian, dan tidak anti modernitas.

\section{SIMPULAN DAN SARAN}

Kartun adalah segmen tontonan yang identik dengan anak-anak dan pada derajat tertentu menjadi konsumsi orang dewasa. Di Indonesia, kebutuhan terhadap tontonan kartun didominasi oleh Jepang dan Amerika. Di luar itu, serial kartun dari Malaysia berjudul Upin Ipin baru muncul belakangan, medio 2009 di layar kaca Indonesia. Alasan yang patut diduga adalah karena Upin Ipin menyajikan kedekatan budaya, agama, dan nilai pergaulan.

Di serial Upin Ipin, pemirsa Indonesia barangkali akan simpatik ketika mendapat suguhan scene 'lebaran' dalam bentuk visualitas kartun, satu hal yang absen di kartun Jepang dan Amerika. Lalu, representasi orang kulit kuning, pengenaan pakaian takwa seperti peci dan hijab, adalah kenikmatan visual yang juga mustahil hadir di kartun Jepang dan Amerika.

Ketimbang kartun-kartun di atas, animasi Nussa bisa dibilang menang banyak: tidak saja soal wacana (hyper) nasionalisme yang membuncah di wilayah budaya populer (bahwa animasi Nussa adalah produk anak bangsa), tetapi juga tentang pemenuhan kebutuhan pasar masyarakat muslim kelas menengah urban.

Kendati pada derajat tertentu mengusung wacana konservatisme agama dalam sejumlah episodenya, animasi Nussa tetap mengakomodasi aspek lain yang membuat dirinya relevan dikonsumsi publik, seperti kenikmatan visual dan plot cerita yang khas kelas menengah. Ini sekaligus menjelaskan aspek ideologis yang terselubung di dalam animasi, yaitu: idealisasi keluarga (kelas menengah) Muslim yang bahagia, penuh ketakwaan, sekaligus kekinian, dan tidak anti modernitas. 
Terakhir, beberapa catatan yang masih absen dalam diskusi artikel ini adalah tentang geneaologi wacana yang diadopsi animasi Nussa untuk mengungkap bahwa dia sebetulnya berkiblat ke mana. Bahasan tentang kenapa animasi Nussa tidak mengadopsi aspek-aspek kultural-tradisional seperti ziarah kubur dan, sebaliknya, malah mengglorifikasi struktur (pasca) modernitas juga menjadi kelemahan dari artikel ini. Padahal jika kita perhatikan lebih detail, karakter Nussa beraras pada tiga kata kunci: agama, sains, dan akhlaq. Tiga kata kunci itu seolah menyimpan romantisme kejayaan abad klasik dan kegelapan abad 20 umat Islam. Kombinasi antara agama dan hard-science adalah pantulan mimpi umat Islam modern yang rindu terhadap capaian teknis namun cuek terhadap capaian abstrak. Umat Islam modern mengandalkan doktrin sebagai pendisiplinan pikiran dan perilaku, dibanding mengandalkan nalar kritis ataupun keberanian bertanya.

\section{REFERENSI}

Alvara Research Center. (2019). Indonesia Moslem Report 2019: "The Challenges of Indonesia Moderate Moslems."

Bayat, A. (1996). The Coming of a Post-Islamist Society. In Critique.

Debord, G. (n.d.). Society of The Spectacle. Rebel Press.

Fiardi, M. H. (2021). Peran Dakwahtainment Akun Channel Youtube Jeda Nulis terhadap Pemuda Tersesat oleh Habib Hussein Ja'far. Jurnal Riset Mahasiswa Dakwah Dan Komunikasi, 3, 76-85.

Gaines, E. (2010). Media Literacy and Semiotics.

Hall, S. (1997). The Work of Representation. In S. Hall (Ed.), Representation. SAGE Publications.

Haq, N. (n.d.). Nussa, Anak Impian Era 4.0. Islami.Co. Retrieved November 23, 2021, from https://islami.co/nussa-anak-impian-era-4-0/

Hastanto, I. (2021, January 12). Trailer Film Animasi "Nussa" Picu Polemik Basi: Mengkritik Film yang Belum Ditonton. https://www.vice.com/id/article/qjpebv/film-animasi-nussa-buatan-visinema-dikritikdianggap-promosi-islam-yang-kearab-araban

Heryanto, A. (2018). Identitas dan Kenikmatan. KPG.

Heychael, M. (2018). Logika Zalim di Balik Tayangan Azab. https://www.remotivi.or.id/amatan/498/logikazalim-di-balik-tayangan-azab

Hoesterey, J. B. (2008). Marketing Morality: The Rise, Fall, and Rebranding of Aa Gym. In Greg Feally \& Sally White (Eds.), Expressing Islam: Religious Life and Politics in Indonesia . ISEAS Publishing.

Idris, M. (2020, March 7). Rincian Terbaru Daftar Gaji PNS 2020 Golongan I hingga IV. Kompas.Com. https://money.kompas.com/read/2020/03/07/124745826/rincian-terbaru-daftar-gaji-pns-2020golongan-i-hingga-iv?page=all

Kuntowijoyo. (2019). Muslim Tanpa Masjid. IRCiSoD.

Kurniawan, A. (2018, June 25). Hukum Jabat Tangan atau Mushafahah dengan Lawan Jenis Bukan Mahram. Nu.or.Id. https://islam.nu.or.id/post/read/92144/hukum-jabat-tangan-atau-mushafahah-dengan-lawanjenis-bukan-mahram

Kurniawan, A. (2021, June 21). Menghakimi Nussa Rara dengan Narasi Taliban Itu Menyedihkan Sekali. Islami.Co. https://islami.co/menghakimi-nussa-rara-dengan-narasi-taliban-itu-menyedihkan-sekali/

Kutanto, H. (2017). Strategi Programming dalam Pengemasan Program “Hafiz Indonesia 2015" RCTI untuk Memperoleh Rating Share Tinggi. Communication, 2. www.KPI.GO.id

Lidwina, A. (2021, February 17). 94\% Orang Indonesia Akses YouTube dalam Satu Bulan Terakhir. Katadata.Co.Id. https://databoks.katadata.co.id/datapublish/2021/02/17/94-orang-indonesia-akses-youtube-dalamsatu-bulan-terakhir

Morgan, T., \& Purje Lauren. (2016, August 10). An Illustrated Guide to Guy Debord's 'The Society of the Spectacle".' Hyperallergic.Com. https://hyperallergic.com/313435/an-illustrated-guide-to-guy-debordsthe-society-of-the-spectacle/

Muzakki, A. (2012). Islamic Televangelism in Changing Indonesia: transmission, Authority, and The Politics of Ideas. In P. N. Thomas \& P. Lee (Eds.), Global and Local Televangelism. Palgrave Macmillan.

Noviani, R. (2020). Politik Representasi di Era Serba Media. In W. Udasmoro (Ed.), Gerak Kuasa: Politik Wacana, Identitas, dan Ruang/Waktu dalam Bingkai Kajian Budaya dan Media. KPG.

Nussa Official Youtube Channel. (2018, October 25). About Nussa. Nussa Official Yuotube Channel. https://www.youtube.com/c/NussaOfficialSeries/about

Nuswantoro, A. R. (2012). Aspek Ekonomi Politik Animasi Upin. Jurnal Komunikasi, 1, 419-428.

Oktafiani, D. (2018, December 20). Lebih Dekat dengan Nussa, Animasi Karya Anak Bangsa. Detik.Com. https://hot.detik.com/spotlight/d-4351813/lebih-dekat-dengan-nussa-animasi-karya-anak-bangsa 
Purnama, Y. (2018, June 21). Saudariku Jangan Upload Fotomu. Muslim.or.Id. https://muslim.or.id/39374saudariku-jangan-upload-fotomu.html

Riswan, K. K. (2021, June 30). Bank Dunia: Pekerjaan kelas menengah jalan menuju Indonesia sejahtera. Antaranews.Com. https://www.antaranews.com/berita/2240134/bank-dunia-pekerjaan-kelasmenengah-jalan-menuju-indonesia-sejahtera

Saefulloh, A. (2009). Dakwahtainment: Komodifikasi Industri Media di Balik Ayat Tuhan. Jurnal Dakwah Dan Komunikasi, 3(2), 255-269.

Sofjan, D. (2012). Gender Construction in Dakwahtainment: A Case Study of Hati ke Hati Bersama Mamah Dedeh. Al-Jami'ah, 50, 58-74.

Supriansyah. (2020, May 14). Sisi Lain Nussa-Rara, Menyaksikan 'Islam Kaku' Diajarkan via Layar Televisi Kita. Islami.Co. https://islami.co/sisi-lain-nussa-rara-menyaksikan-islam-kaku-diajarkan-via-layar-televisi-kita/

Thaniago, R., \& Arief, Y. (2014). Perempuan Tanpa Otonomi: Wajah Ideologi Dominan dalam Sinetron Ramadhan.

Utomo, W. P. (2013, July 30). Ramadhan, Televisi, dan Kelesuan Rohani. Remotivi. https://www.remotivi.or.id/amatan/146/ramadhan-televisi-dan-kelesuan-rohani

Yuniar, N. (2021, June 6). Animasi "Nussa" tayang perdana di Korea Selatan. Antara News. https://www.antaranews.com/berita/2214274/animasi-nussa-tayang-perdana-di-korea-selatan

Zuhad, A. (2021, January 12). Angga Dwimas Sasongko Balas Tuduhan Denny Siregar Soal Film Nussa. Kompas.Tv. https://www.kompas.tv/article/137353/angga-dwimas-sasongko-balas-tuduhan-dennysiregar-soal-film-nussa 